\title{
The antidiabetic effect of Geigeria alata is mediated by enhanced insulin secretion, modulation of $\beta$-cell function, and improvement of antioxidant activity in streptozotocin-induced diabetic rats
}

\author{
Rahman M Hafizur, Randa Babiker ${ }^{1,2}$, Sakina Yagi ${ }^{1}$, Sidra Chishti, Nurul Kabir and M Iqbal Choudhary ${ }^{3,4}$ \\ Dr Panjwani Center for Molecular Medicine and Drug Research, International Center for Chemical and Biological Sciences, University of Karachi, Karachi \\ 75270, Pakistan \\ ${ }^{1}$ Department of Botany, Faculty of Science, University of Khartoum, PO Box 321, Khartoum, Sudan \\ ${ }^{2}$ Department of Botany, Faculty of Science, University of Kordofan, Kordofan, Sudan \\ ${ }^{3}$ H.E.J. Research Institute of Chemistry, International Center for Chemical and Biological Sciences, University of Karachi, Karachi 75270, Pakistan \\ ${ }^{4}$ Department of Chemistry, College of Science, King Saud University, Riyadh 11451, PO Box 2455, Saudi Arabia \\ (Correspondence should be addressed to R M Hafizur; Email: hafizur.rahman@iccs.edu)
}

\begin{abstract}
In Sudanese folk medicine, Geigeria alata roots have been used for the management of diabetes for a long time. However, its antidiabetic activity is unreported. In this study, G. alata methanolic extract was tested for its antidiabetic, antioxidant, and $\beta$-cell modulatory effects in a streptozotocin-induced diabetic rat model. In this model of diabetic rats, the oral glucose tolerance test with $G$. alata extract at 125,250 , and $500 \mathrm{mg} / \mathrm{kg}$ doses revealed the efficacy of the $250 \mathrm{mg} / \mathrm{kg}$ dose in improving glucose tolerance comparable to the standard drug glibenclamide. Diabetic rats were treated with a $250 \mathrm{mg} / \mathrm{kg}$ dose of G. alata extract orally for $2 \mathrm{~h}$ (acute) or 14 days (chronic). In the case of acute treatment, the extract lowered blood glucose levels
\end{abstract}

significantly at $120 \mathrm{~min}$ both in nondiabetic and diabetic rats. Chronic treatment of diabetic rats with $250 \mathrm{mg} / \mathrm{kg}$ of G. alata extract resulted in a significant decrease in blood glucose level closer to that of nondiabetic rats. Interestingly, increased serum insulin, improved $\beta$-cell function, and antioxidant status were observed in G. alata-treated diabetic rats. G. alata also showed strong antioxidant and $\alpha$-glucosidase inhibitory activities in in vitro assays. These data show direct evidence that $G$. alata has antidiabetic activity and suggest that the antidiabetic activity is due to enhanced insulin secretion, modulation of $\beta$-cell function, and improvement of antioxidant status.

Journal of Endocrinology (2012) 214, 329-335

\section{Introduction}

The incidence of diabetes is alarmingly increasing throughout the world. One of the worst affected areas appears to be Asia and Africa where diabetes could rise two- to three-folds in the near future. More than $50 \%$ of diabetic patients in the world are from Africa and Asia (Al-Rubeaan 2010), which were recently called the type 2 diabetes red zone. For this particular region, it is crucial to identify effective and low-cost medications for treating diabetes considering the economic constraints. Alternative strategies to the current pharmacotherapy of diabetes such as herbal medicine are urgently needed because of enormous cost and limited access to modern therapies for many rural population in developing countries such as Sudan and Pakistan. Plants are extensively used in the African continent, where up to $90 \%$ of the population still relies on medicinal plants as the principal source of medicines for their health (Hostettmann \& Marston
2002, EL-Kamali \& EL-amir 2010). In Sudan, many traditional plants are being used for the management of different diseases, including diabetes. Among them, Geigeria alata (DC.) is one of the herbs widely used in Sudan against various diseases, including diabetes (EL-Kamali 2009, EL-Kamali \& EL-amir 2010).

G. alata (DC.), commonly known as 'Gud-gad', is an aromatic plant belonging to the Asteraceae family found in northern and central Sudan. G. alata is a glabrous, erect, branched, annual herb, up to $1 \mathrm{~m}$ high with threewinged stems. In Sudanese traditional medicine, G. alata is being used against epilepsy, as an antispasmodic (El Ghazali et al. 1994, 1997), or to treat cough and intestinal complaints (Hostettmann \& Marston 2002, EL-Kamali \& EL-amir 2010). In a recent study, G. alata showed strong immunomodulation inhibitory activity and cell oxidative burst response (Koko et al. 2008). G. alata root is frequently used for the management of diabetes in Sudan (EL-Kamali 2009, EL-Kamali \& EL-amir 
2010). However, no scientific report of its antidiabetic activity has so far been reported despite its long use for the management of diabetes by the Sudanese people.

Phytochemical analysis of G. alata showed that the major phytochemicals are alkaloids, flavonoids, tannins, and volatile oil (Ross et al. 1997, EL-Kamali \& EL-amir 2010). To our knowledge, there are no studies reporting any identified antidiabetic phytochemical isolated from G. alata.

In this study, we tested chronic effects of aqueous methanolic extract of $G$. alata root in vivo in diabetic rats. Streptozotocin (STZ)-induced diabetic rats were treated over a 14-day period, revealing efficiency of the treatment. G. alata extract was found to control blood glucose level, enhance insulin secretion, modulate $\beta$-cell function, and improve antioxidant status in diabetic rats. These observations demonstrate for the first time a direct antidiabetic effect of $G$. alata on rats and provide a rationale for supporting the traditional use of $G$. alata for the management of diabetes by the Sudanese people.

\section{Materials and Methods}

\section{Preparation of extract}

Roots of $G$. alata were collected from north Kordofan on 25 September 2006. Botanical identification and authentication were performed by Dr Wail El Sadig and a voucher specimen no. 41935/HNC was deposited in the Botany Department Herbarium, Faculty of Science, University of Khartoum, Sudan. The powdered dried roots $(400 \mathrm{~g})$ of G. alata were soaked in $80 \%$ aqueous methanol (21) three times for 5 days each at room temperature. The pooled extracts were filtered, concentrated, and evaporated to dryness under vacuum by using a rotary evaporator. Finally, the crude extract was freeze-dried to obtain the experimental extract $(25 \cdot 5 \mathrm{~g})$. The extract yield was $6 \cdot 4 \%$.

The extract was dissolved in distilled water before its administration to the diabetic rats. For treatments, the concentration of G. alata in water was $250 \mathrm{mg} / 5 \mathrm{ml}$ per $\mathrm{kg}$ body weight. To make this, $1 \mathrm{~g}$ G. alata extract was taken into a falcon tube and $20 \mathrm{ml}$ water was added to the extract. The extract was dissolved by putting the tube in a hot water bath with vigorous shaking. In this condition, the extract was dissolved almost completely in water. The dose was calculated and different volume of the extract was administered to the diabetic rats depending on the body weight.

In vitro studies

1,1-Diphenyl-2-picrylhydrazyl radical scavenging activity assay The radical scavenging property of the extract was evaluated by assessing the 1,1-diphenyl-2-picrylhydrazyl (DPPH) scavenging activity according to Fenglin et al. (2004). Propyl gallate was used as a positive control.
$\boldsymbol{\alpha}$-Glucosidase inhibitory assay In vitro assay for $\boldsymbol{\alpha}$-glucosidase inhibitory activity was performed according to Atta-ur-Rahman et al. (2008). Acarbose was used as a positive control.

In vivo studies

Animals and induction of diabetes Wistar rats $(180-220 \mathrm{~g})$ of both sexes from the animal house of the International Center for Chemical and Biological Sciences (ICCBS), University of Karachi, Pakistan, were used throughout the study. The rats were kept and maintained in laboratory experimental animal units under standard conditions of temperature and humidity with a $12 \mathrm{~h}$ light:12 h darkness cycle. The rats were maintained in clean cages with ad libitum access to water and food. All animals were treated according to the guideline for care and use of laboratory animals with the approval of the Institutional Ethics Committee of the ICCBS, University of Karachi, Pakistan.

A $55 \mathrm{mg} / \mathrm{kg}$ solution of STZ (Wako Pure Chemical, Osaka, Japan) in $1.0 \mathrm{ml}$ citrate buffer $(0 \cdot 1 \mathrm{M}, \mathrm{pH} 4 \cdot 5)$ was i.p. injected to overnight fasted rats. Nondiabetic control rats were injected with vehicle only.

After 7 days of STZ induction, fasting blood glucose levels were determined using a glucometer (Roche Diagnostics). The rats with fasting blood glucose levels of more than $15 \mathrm{mmol} / 1$ were used for this study.

Oral glucose tolerance test with $G$. alata extract in diabetic rats Thirty diabetic rats were divided into five groups of six rats each. Group 1, treated with distilled water, was used as the negative control. Group 2, treated with $5 \mathrm{mg} / \mathrm{kg}$ glibenclamide (Gb), was taken as the positive control. Groups 3, 4, and 5 served as treated groups and received the $G$. alata extract at doses of 125, 250, and $500 \mathrm{mg} / \mathrm{kg}$ respectively.

All the diabetic rats were fasted overnight $(14 \mathrm{~h})$ before the oral glucose tolerance test (OGTT) test was done. Thirty minutes following the extract or $\mathrm{Gb}$ treatment, each rat was given an oral glucose load, $3 \mathrm{~g} / \mathrm{kg}$ body weight. All rats were tested for blood glucose levels at $-30 \mathrm{~min}$ (just before the administration of the extract or $\mathrm{Gb}$ ) and at $0,30,60,120$, and $180 \mathrm{~min}$ after the glucose load. OGTT was also performed in the normal control rats for comparison.

Acute extract treatment G. alata extract $(250 \mathrm{mg} / \mathrm{kg}$ per $5 \mathrm{ml}$ water) was fed to overnight fasted nondiabetic and diabetic rats, and blood glucose levels were measured at 0, 60, and $120 \mathrm{~min}$. Nondiabetic and diabetic control rats received $2 \mathrm{ml}$ of water in place of extract.

Chronic extract treatment The experimental rats were divided into four groups of seven rats each: Group I, normal control rats; Group II, untreated diabetic rats; Group III, G. alata-treated diabetic rats; and Group IV, Gb-treated 


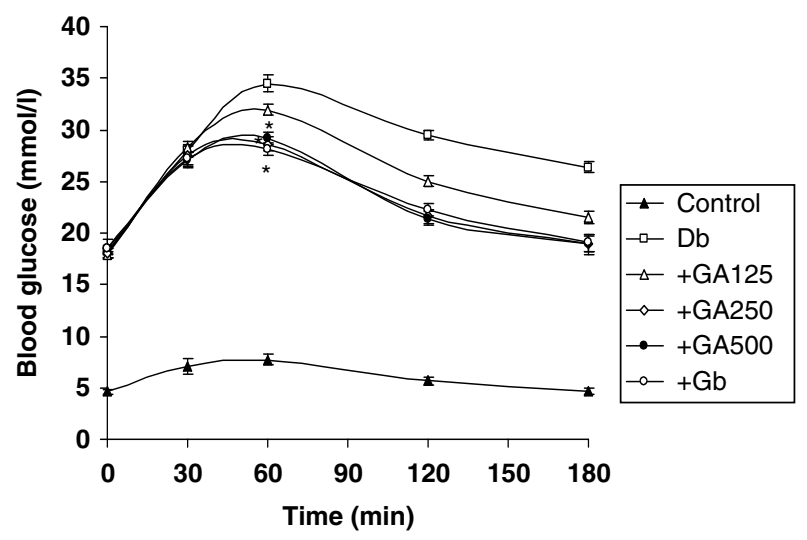

Figure 1 Effects of different doses of Geigeria alata extract on OGTT in STZ-induced diabetic rats. G. alata extract was administered orally $30 \mathrm{~min}$ before oral glucose $(3 \mathrm{~g} / \mathrm{kg})$ load and blood glucose monitored at 0, 30, 60, 120, and $180 \mathrm{~min}$. Glibenclamide (5 mg/kg) was used as a reference drug. Values are mean \pm S.E.M. for six rats per group. Db: diabetic rats treated with glucose only; + GA125, +GA250, and + GA500: diabetic rats treated with glucose plus $G$. alata extract of 125,250 , and $500 \mathrm{mg} / \mathrm{kg}$, respectively; + Gb: diabetic rats treated with glucose plus glibenclamide; Control: nondiabetic rats treated with only glucose. ${ }^{*} P<0 \cdot 001$ vs 60 -min value of diabetic control.

diabetic rats. In the case of $G$. alata-treated diabetic rats, the extract was fed orally at a dose of $250 \mathrm{mg} / \mathrm{kg}$ per $5 \mathrm{ml}$ water once daily for 14 days. Normal control rats and untreated diabetic rats received equal volumes of water in place of the extract, while $\mathrm{Gb}(5 \mathrm{mg} / \mathrm{kg})$ was given orally once daily to the Gb-treated diabetic rats. The body weight was measured every day and the dose was calculated accordingly. The fasting blood glucose level was measured every week until the end of the experimental period.

Collection of blood samples and estimation of biochemical parameters For the purpose of biochemical estimation, blood samples were collected from the tail vein on day 1 after overnight fasting. Finally, after 14 days of extract treatment, the rats were sacrificed and blood was collected for biochemical parameters. Blood samples were allowed to clot and serum was separated by centrifugation. Serum samples were stored at $-30^{\circ} \mathrm{C}$ for biochemical assay.

Fasting serum glucose was measured by the glucose oxidase method (Randox Laboratories, Antrim, UK) and fasting serum insulin was measured using ultrasensitive rat insulin ELISA kit (Crystal Chem, Inc., Downers Grove, IL, USA) on day 1 and day 15 according to the manufacturer's protocol. Serum triglyceride was measured by the enzymatic colorimetric method and serum total cholesterol was measured by the cholesterol oxidase/peroxidase method (Randox Laboratories). Total antioxidant status (TAS) was measured using an ABTS substrate assay kit (Randox Laboratories) according to the manufacturer's instructions. Serum creatinine, alanine aminotransferase (ALT), and aspartate aminotransferase (AST) were measured by standard techniques using the Reflotron Plus Dry Chemistry Analyzer (Roche Diagnostics).

Assessment of $\boldsymbol{\beta}$-cell function $\beta$-Cell function (HOMA B\%) was measured from fasting glucose $(\mathrm{mmol} / \mathrm{l})$ and fasting serum insulin (pmol/l) concentration by homeostasis model assessment (HOMA) using HOMACIGMA Software (Oxford, UK), where HOMA B\% indicates $\beta$-cell function (Matthews et al. 1985).

Toxicity evaluation The extract of G. alata was tested for acute toxicity (if any) in rats. To determine acute toxicity, a single oral administration of the G. alata extract of different doses $(0 \cdot 25,0 \cdot 5,1 \cdot 0,1 \cdot 5$, and $2 \cdot 0 \mathrm{~g} / \mathrm{kg})$ was followed for different groups of Wistar rats $(n=6)$ of either sex. Mortality and general behavior of the animals were observed continuously for the initial $4 \mathrm{~h}$ and intermittently for the next $6 \mathrm{~h}$ and then again at 24,48 , and $72 \mathrm{~h}$, following extract administration. After 14 days of daily treatment with the extract, serum creatinine, ALT, and AST were measured as markers of toxicity of the kidney and the liver, respectively, to check whether the extract had any toxic effect on chronic treatment.

Statistical analysis Statistical analyses were performed by using the SPSS 12.0 statistical package for Windows (SPSS, Inc., Chicago, IL, USA). All values were expressed as mean \pm S.D. or mean \pm S.E.M. Statistical difference among the groups was assessed by one-way ANOVA with Dunnett's post hoc test. To compare data within the group, paired $t$-test (two-tailed) was performed. $P$ values $<0 \cdot 05$ were considered significant.

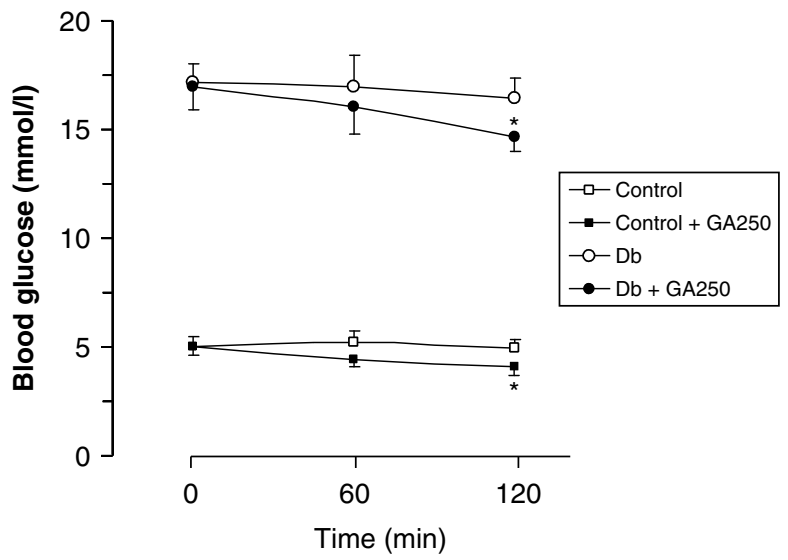

Figure 2 Acute effects of Geigeria alata extract on fasting blood glucose levels of nondiabetic and diabetic rats. Values are mean \pm s.D. for six rats per group. Control, nondiabetic control rats; Control + GA250, control rats treated with G. alata extract of $250 \mathrm{mg} / \mathrm{kg}$; Db, diabetic control rats; Db + GA250, diabetic rats treated with $G$. alata extract of $250 \mathrm{mg} / \mathrm{kg} .{ }^{*} P<0 \cdot 05$ vs their 0 -min value. 


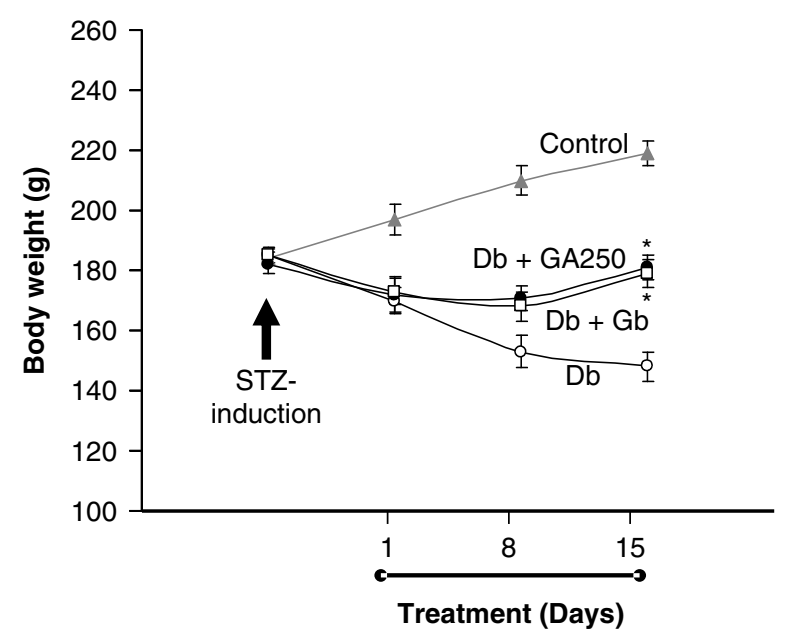

Figure 3 Changes of body weight of adult Wistar rats after STZ induction and effect of chronic extract treatment on diabetic rats. Values are mean \pm S.E.M. for seven rats in each group. $\mathrm{Db}$, diabetic control rats; $\mathrm{Db}+\mathrm{GA} 250$, diabetic rats treated with Geigeria alata extract of $250 \mathrm{mg} / \mathrm{kg}$; $\mathrm{Db}+\mathrm{Gb}$, diabetic rats treated with glibenclamide; Control, nondiabetic control rats. ${ }^{*} P<0 \cdot 001$ vs diabetic control.

\section{Results}

G. alata has strong antioxidant and $\alpha$-glucosidase inhibitory activities in vitro

G. alata was evaluated for its radical scavenging activity by using DPPH. G. alata $(0.5 \mathrm{mg} / \mathrm{ml})$ showed $91 \%$ radical scavenging activity (data not shown), which was indicated by a significant decrease in the absorbance of DPPH radicals.

The $\alpha$-glucosidase inhibitory assay showed that $G$. alata has $72 \%$ inhibitory activity against $\alpha$-glucosidase at a concentration of $0.5 \mathrm{mg} / \mathrm{ml}$ (data not shown). This inhibitory activity suggests that this extract can delay glucose absorption, which may be a possible mechanism of its antidiabetic activity.

G. alata shows antidiabetic activity with acute treatment of diabetic rats The effects of oral administration of 125,250 , and $500 \mathrm{mg} / \mathrm{kg}$ doses of G. alata extract on blood glucose levels of STZ-induced diabetic rats challenged with a glucose load are presented in Fig. 1. It was found that the blood glucose reached the peak level at $60 \mathrm{~min}$ after glucose load in the diabetic rats. At $60 \mathrm{~min}, 250$ and $500 \mathrm{mg} / \mathrm{kg}$ doses of $\mathrm{G}$. alata extract produced significantly lower blood glucose levels as compared to the vehicle. A maximum decrease of $17 \cdot 1 \%(P<0 \cdot 001)$ was observed with $250 \mathrm{mg} / \mathrm{kg}$ of extract at $60 \mathrm{~min}$. The dose $500 \mathrm{mg} / \mathrm{kg}$ also produced a significant $(P<0.001)$ decrease $(15.3 \%)$ in blood glucose level at $60 \mathrm{~min}$. However, the dose $125 \mathrm{mg} / \mathrm{kg}$ did not produce a significant decrease $(7 \cdot 4 \%)$ in blood glucose level at $60 \mathrm{~min}$. The standard drug $\mathrm{Gb}$ caused a significant decrease $(18 \cdot 5 \%)$ in blood glucose level at $60 \mathrm{~min}$.
Acute effects of $G$. alata extract on blood glucose levels of control and diabetic rats are shown in Fig. 2. After feeding the extract to the control rats, the blood glucose level decreased significantly at $120 \mathrm{~min}(P=0.014)$ compared to its initial value $(0 \mathrm{~min})$. In diabetic rats, the extract showed a reduction in blood glucose level that was not statistically significant at $60 \mathrm{~min}(P=0.07)$; however, the reduction was significant only at $120 \mathrm{~min}(P=0 \cdot 02$; Fig. 2$)$.

G. alata shows antidiabetic and antioxidant activities with chronic treatment of diabetic rats The variations in body weight of normal control, untreated diabetic, and diabetic rats treated with G. alata extract are shown in Fig. 3. During the experimental periods, a gradual gain in body weight was observed in the control rats, whereas a gradual reduction in body weight was observed in the STZ-induced rats. The body weight of untreated diabetic rats was decreased significantly compared to that of control rats $(P<0 \cdot 001)$. When the diabetic rats were treated with $G$. alata $(250 \mathrm{mg} / \mathrm{kg})$ extract or $\mathrm{Gb}(5 \mathrm{mg} / \mathrm{kg})$ for 14 days, their body weight improved significantly (Fig. 3).

Chronic effects of the G. alata extract on fasting blood glucose levels of STZ-induced diabetic rats are shown in Fig. 4. After 7 days of STZ induction, the blood glucose level was significantly increased in the rats compared with the vehicle group $(P<0 \cdot 001)$. After 14 days of daily treatment with the extract, the fasting glucose level of $G$. alata-treated

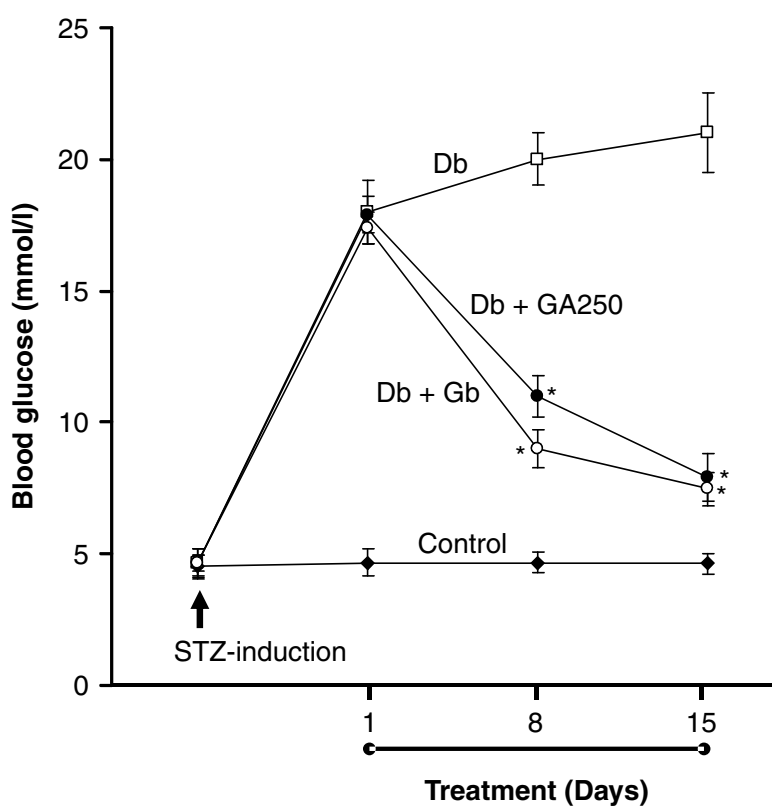

Figure 4 Chronic effect of methanolic extract of Geigeria alata on fasting blood glucose $(\mathrm{mmol} / \mathrm{l})$ in diabetic rats. Values are mean \pm S.E.M. for seven rats per group. Db, diabetic control rats; $\mathrm{Db}+\mathrm{GA} 250$, diabetic rats treated with $G$. alata extract of $250 \mathrm{mg} / \mathrm{kg}$; $\mathrm{Db}+\mathrm{Gb}$, diabetic rats treated with glibenclamide; Control, nondiabetic control rats. ${ }^{*} P<0 \cdot 001$ vs diabetic control. 


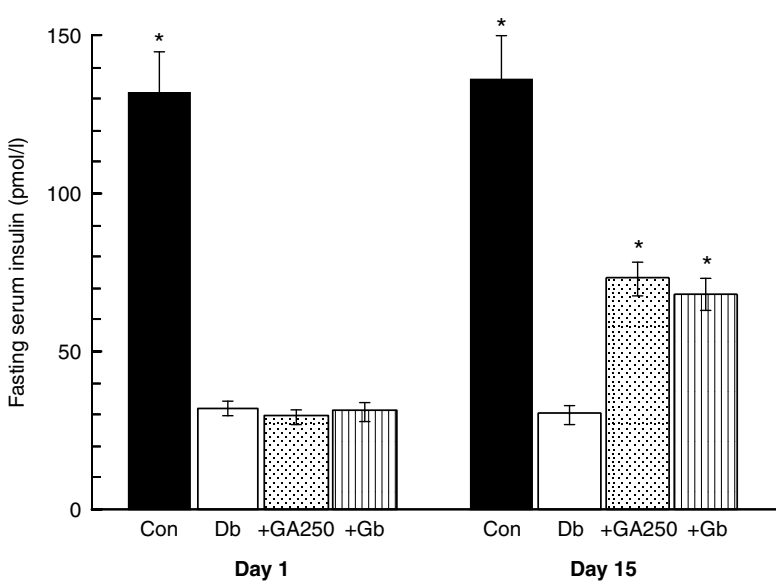

Figure 5 Chronic effect of methanolic extract of Geigeria alata on fasting serum insulin $(\mathrm{pmol} / \mathrm{l})$ in diabetic rats. Values are mean \pm S.E.M. for seven rats per group. Db, diabetic control rats; + GA250, diabetic rats treated with G. alata extract of $250 \mathrm{mg} / \mathrm{kg}$; $+\mathrm{Gb}$, diabetic rats treated with glibenclamide; Con, nondiabetic control rats. ${ }^{*} P<0 \cdot 001$ vs diabetic control.

diabetic rats decreased significantly from $17 \cdot 9 \pm 1 \cdot 02 \mathrm{mmol} / 1$ on day 1 to $7 \cdot 34 \pm 0.33 \mathrm{mmol} / 1(P<0 \cdot 001)$ on day 15 , corresponding to $60 \%$ fasting blood glucose reduction. $\mathrm{Gb}$ also reduced the fasting blood glucose level of diabetic rats.

Fasting serum insulin levels in diabetic rats were significantly decreased as compared to control rats $(32 \cdot 05$ \pm 2.25 vs $132.30 \pm 15.95 \mathrm{pmol} / 1, P<0.001$; Fig. 5). Very little changes in the above-mentioned pattern of serum insulin levels were observed in control and untreated diabetic rats during the experimental periods (1-15 days). Interestingly, a significant increase in serum insulin level $(P<0 \cdot 001)$ was found when the diabetic rats were treated with $G$. alata extract for 14 days $(73 \cdot 10 \pm 5 \cdot 35 \mathrm{pmol} / \mathrm{l})$, as compared to untreated diabetic rats $(29 \cdot 87 \pm 2 \cdot 48 \mathrm{pmol} / \mathrm{l})$. The standard drug $\mathrm{Gb}$ also increased the serum insulin level significantly from day 1 to day $15(P<0 \cdot 001)$.

$\beta$-cell function (HOMA B\%) was significantly decreased $(P<0 \cdot 001)$ in diabetic rats $(15 \cdot 8 \pm 2 \cdot 7 \%)$ compared to control rats $(142 \cdot 4 \pm 16 \cdot 2 \%$; Fig. 6). No significant changes in the above-mentioned pattern of $\beta$-cell function were observed in control and untreated diabetic rats during the experimental periods. However, significant improvement $(P<0 \cdot 001)$ of $\beta$-cell function was observed in $G$. alata-treated diabetic rats $(72 \cdot 4 \pm 7 \cdot 5 \%)$ compared to untreated diabetic rats $(15 \cdot 7 \pm$ 3.9\%; Fig. 6). Gb also significantly improved $\beta$-cell function in diabetic rats.

Figure 7 shows the chronic effect of G. alata extract on total cholesterol and triglyceride levels. STZ-induced diabetic rats did not show any significant change in the serum total cholesterol during the experimental periods (Fig. 7A). Even the administration of $G$. alata or $\mathrm{Gb}$ did not significantly affect the total cholesterol level (Fig. 7A). The serum triglyceride of the diabetic rats was decreased significantly $(P<0 \cdot 05)$ at day $15(0.57 \pm 0.02 \mathrm{mmol} / \mathrm{l})$ compared to day 1 $(0.76 \pm 0.03 \mathrm{mmol} / \mathrm{l} ;$ Fig. $7 \mathrm{~B})$. The decreased triglyceride value of the diabetic rats may be due to the burning of fats during the severe diabetic stage in order to provide energy. Diabetic rats fed with G. alata extract showed no significant changes in triglyceride level compared to untreated diabetic rats.

Changes of TAS in each group of rats are shown in Fig. 8. TAS $(P<0.001)$ was found significantly decreased in the diabetic rats $(0.82 \pm 0.08 \mathrm{mmol} / \mathrm{l})$ compared to the control rats $(1.78 \pm 0.09 \mathrm{mmol} / \mathrm{l})$. However, daily treatment of the diabetic rats with $G$. alata for 14 days significantly improved the TAS $(1 \cdot 19 \pm 0 \cdot 11 \mathrm{mmol} / \mathrm{l})$ comparable to Gb-treated rats $(1 \cdot 16 \pm 0 \cdot 12 \mathrm{mmol} / \mathrm{l})$.

Toxicity of G. alata extract In toxicity evaluation by brine shrimp lethality bioassay, methanolic extract did not show any toxicity, reflecting a good safety profile at a preliminary level (data not shown). Furthermore, in the MTT assay of cytotoxicity with methanolic extract, no toxic effects were observed (data not shown). The in vivo acute toxicity results showed no mortality up to the dose of $2000 \mathrm{mg} / \mathrm{kg}$ body weight. Serum creatinine, ALT, and AST were measured as markers of toxicity to check whether the extract had any toxic effect on chronic treatment. The results showed that there was no significant increase in the serum creatinine, ALT, and AST levels after the chronic treatment with the extract.

\section{Discussion}

The in vitro $\alpha$-glucosidase inhibitory activity of G. alata root extract suggests a role for its antidiabetic activity. Furthermore, the strong antioxidant activity of G. alata suggests a

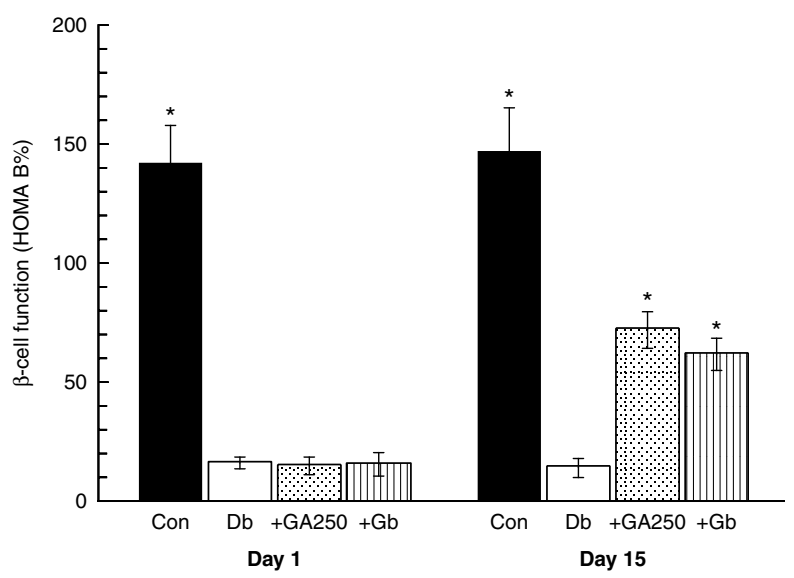

Figure 6 Chronic effect of Geigeria alata extract on $\beta$-cell function (HOMA B\%) in the diabetic rats. Values are mean \pm S.E.M. for seven rats per group. $\mathrm{Db}$, diabetic control rats; $+\mathrm{GA} 250$, diabetic rats treated with $G$. alata extract of $250 \mathrm{mg} / \mathrm{kg}$; $+\mathrm{Gb}$, diabetic rats treated with glibenclamide; Con, nondiabetic control rats. $* P<0 \cdot 001$ vs diabetic control. 

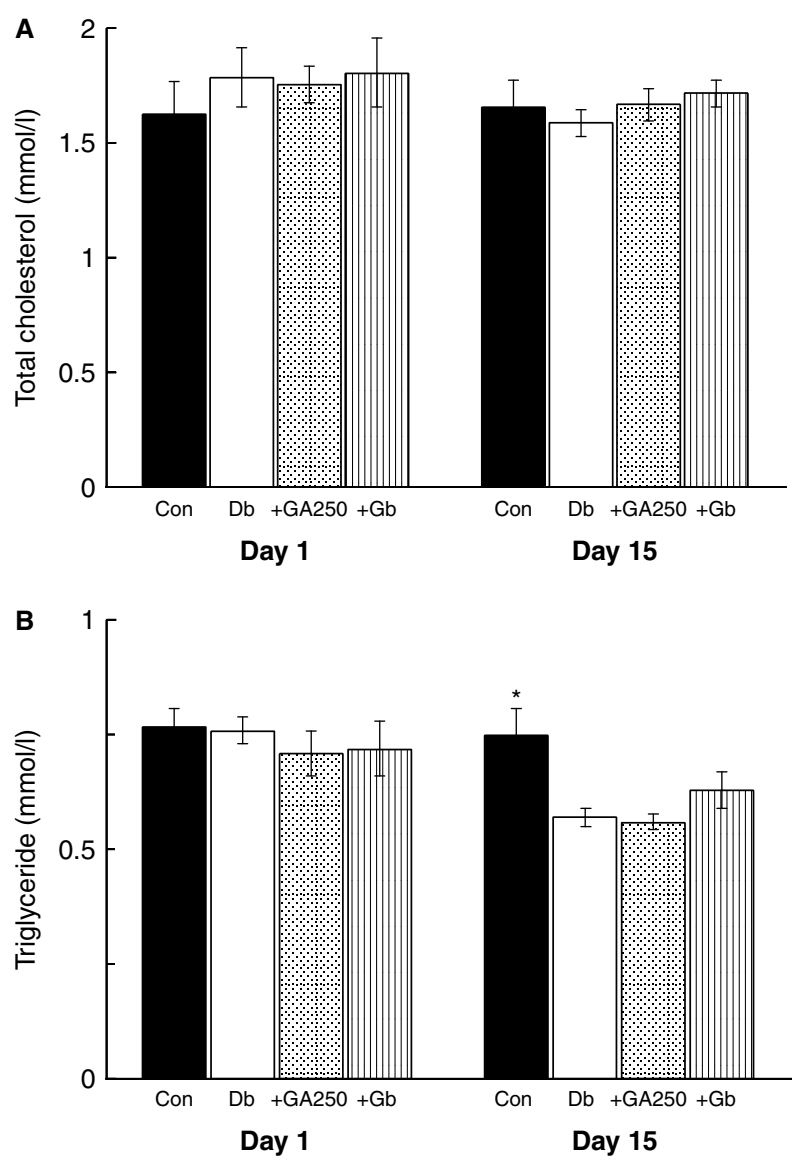

Figure 7 Chronic effect of Geigeria alata extract on total cholesterol (A) and triglyceride (B) levels in diabetic rats. Values are mean \pm S.E.M. for seven rats per group. $\mathrm{Db}$, diabetic control rats; + GA250, diabetic rats treated with G. alata extract of $250 \mathrm{mg} / \mathrm{kg}$; $+\mathrm{Gb}$, diabetic rats treated with glibenclamide; Con, nondiabetic control rats. ${ }^{*} P<0.05$ vs diabetic control.

possible correlation between antioxidant and antidiabetic activities. Because of these in vitro results, we were tempted to investigate the scientific basis of the use of $G$. alata for the management of diabetes by the Sudanese people. This was performed by looking at the antidiabetic activity of G. alata root extract on STZ-induced diabetic rats.

The OGTT results of 125,250 , and $500 \mathrm{mg} / \mathrm{kg}$ doses of G. alata showed that $G$. alata has a dose-dependent improvement of glucose tolerance, and the dose of $250 \mathrm{mg} / \mathrm{kg}$ showed the maximum improvement of glucose tolerance (Fig. 1).

In the acute experiment, $125 \mathrm{mg} / \mathrm{kg}$ G. alata had little effect on OGTT, whereas 250 and $500 \mathrm{mg} / \mathrm{kg}$ had similar effects and improved glucose tolerance significantly (Fig. 1). It was found that the dose of $250 \mathrm{mg} / \mathrm{kg}$ produced the highest reduction in blood glucose level at $60 \mathrm{~min}$ and no appreciable reduction in this level was observed on further increase of the dose. One possible explanation for the relative lack of a good dose-response effect is that the minimum and maximum effective dose might be in a very narrow range, representing possible receptor saturation or a similar effect. Furthermore, the dose of $125 \mathrm{mg} / \mathrm{kg}$ of G. alata in a 7-day treatment (subchronic) failed to produce a significant blood glucose-lowering effect (data not shown), whereas the dose $250 \mathrm{mg} / \mathrm{kg}$ significantly decreased the blood glucose level (Fig. 4). Therefore, the dose of $250 \mathrm{mg} / \mathrm{kg}$ was selected for chronic treatment in STZ-induced diabetic rats.

The $250 \mathrm{mg} / \mathrm{kg}$ G. alata extract significantly improved glucose tolerance in diabetic rats comparable to the standard drug Gb (Fig. 1). In view of the similarity between the effects of G. alata and Gb, it can be suggested that the mode of action of $G$. alata extract might be mediated by an enhanced insulin secretion. This assumption was confirmed by our biochemical examination, which revealed enhanced insulin secretion (Fig. 5) and improvement of $\beta$-cell function (Fig. 6).

The extract showed hypoglycemic activity in nondiabetic control rats (Fig. 2) and the effectiveness of the extract in diabetic rats indicates that the hypoglycemic effect of G. alata is probably mediated by improving either insulin secretion or insulin action. Improvement in glucose tolerance by oral administration of G. alata extract (Fig. 1) supports that this is probably mediated by an enhanced insulin secretion.

In this model of diabetic rats, decreased body weight was observed (Fig. 3). The decreased body weight in diabetic rats could be due to the catabolism of fats and the degradation

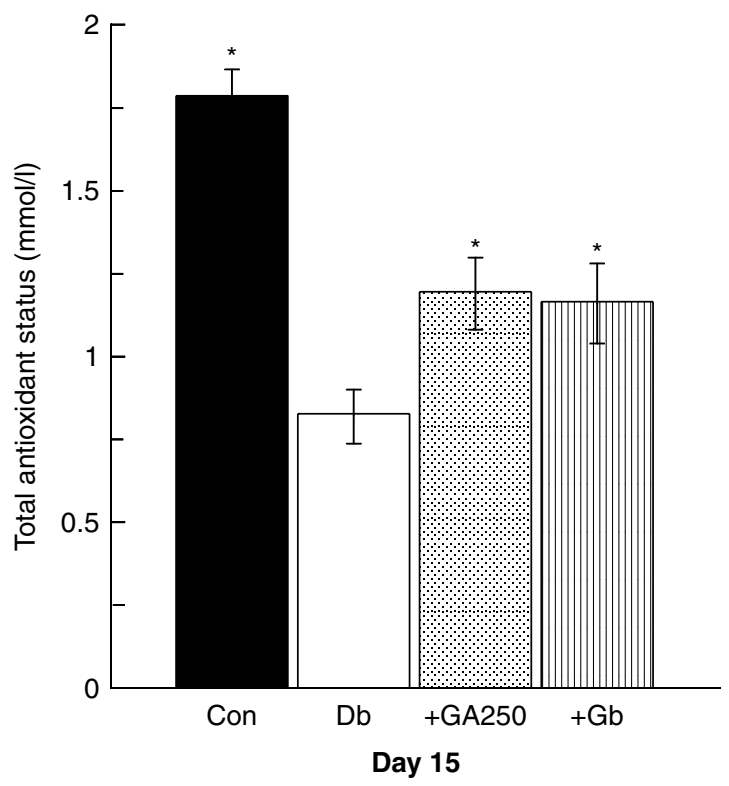

Figure 8 Chronic effect of Geigeria alata extract on total antioxidant status of the experimental rats. Values are mean \pm s.E.M. for seven rats per group. Db, diabetic control rats; $+\mathrm{GA} 250$, diabetic rats treated with $G$. alata extract of $250 \mathrm{mg} / \mathrm{kg} ;+\mathrm{Gb}$, diabetic rats treated with glibenclamide; Con, nondiabetic control rats. $* P<0 \cdot 001$ vs diabetic control. 
of structural proteins (Hakim et al. 1997, Kamalakkannan \& Prince 2006). Oral administration of $G$. alata root extract for 14 consecutive days to diabetic rats improved their body weight. This could be due to better control of the hyperglycemic state in diabetic rats (Fig. 4). Decreased fasting glucose could improve the body weight in diabetic rats, and this is consistent with other studies (Pari \& Saravanan 2004, Nagarajan et al. 2005).

Another possible mechanism of the antidiabetic activity of $G$. alata, in addition to improving insulin secretion, is by delayed glucose absorption. Delayed glucose absorption is usually due to the inhibition of enzyme $\boldsymbol{\alpha}$-glucosidase, located at the intestinal surface. G. alata showed significant $\alpha$-glucosidase inhibitory activity in our in vitro assay. These results suggest that reduction in blood glucose level by $G$. alata may be achieved by the inhibition of glucose absorption at the intestine and/or the promotion of insulin secretion from the pancreatic $\beta$-cells.

Antioxidants have been hypothesized to have a protective effects against the development of diabetes (Oberley 1988). It seems plausible that a sufficient intake of antioxidants may play an important role in the protection against diabetes. In this study, the in vitro antioxidant potential and in vivo improvement of TAS by the extract (Fig. 8) are comparable with those of standard drugs propyl gallate and $\mathrm{Gb}$. In experiments with ascorbic acid (vitamin $\mathrm{C}$, a naturally occurring organic compound with antioxidant properties), we found that at a dose of $250 \mathrm{mg} / \mathrm{kg}$, ascorbic acid alone partially controlled the blood glucose level in this model of diabetic rats (data not shown). Therefore, the strong antioxidant property of $G$. alata may improve the diabetic state.

In conclusion, this study revealed, for the first time, the antidiabetic activity of $G$. alata in an animal model of diabetes. Our data strongly suggest that the antidiabetic activity is due to enhanced insulin secretion, modulation of $\beta$-cell function, and improvement in antioxidant status. The extract did not show any toxicity both in in vitro and in vivo studies, implying a relative lack of toxicity. These observations provide a rationale for supporting the traditional use of $G$. alata by the Sudanese people.

\section{Declaration of interest}

The authors declare that there is no conflict of interest that could be perceived as prejudicing the impartiality of the research reported.

\section{Funding}

This work was supported by grants from Pakistan Academy of Sciences (5-9/3394/PAS/), Islamabad, Pakistan, and from Islamic Development Bank (70/HEJ-MAPRI) under the joint research project between the International Center for Chemical and Biological Sciences (ICCBS), University of Karachi, Pakistan, and the Medicinal and Aromatic Plants Research Institute (MAPRI), Khartoum, Sudan.

\section{Acknowledgements}

We are thankful to training administration of the Ministry of Higher Education, Sudan, for financial support for R B to visit H.E.J. Research Institute of Chemistry, ICCBS, University of Karachi, Pakistan.

\section{References}

Al-Rubeaan K 2010 Type 2 diabetes mellitus red zone. International Journal of Diabetes Mellitus 2 1-2. (doi:10.1016/j.ijdm.2009.12.009)

Atta-ur-Rahman, Zareen S, Choudhary MI, Akhtar MN \& Khan SN 2008 $\alpha$-Glucosidase inhibitory activity of triterpenoids from Cichorium intybus. Journal of Natural Products 71 910-913. (doi:10.1021/np800001v)

El Ghazali GEB, El Tohami MS \& El Elegami AAB 1994 Medicinal plants of the white nile provinces. In Medicinal Plants of the Sudan, Part 3, pp 56. Ed El Ghazali GEB. National Center for Research, Medicinal \& Aromatic Plants Research Institute, Khartoum, Sudan.

El Ghazali GEB, El Tohami MS, El Elegami AAB 1997. Medicinal plants of Northern Kordofan. In Medicinal Plants of the Sudan, Part 4, pp 69. Ed El Ghazali GEB. National Center for Research, Medicinal \& Aromatic Plants Research Institute, Khartoum, Sudan.

EL-Kamali HH 2009 Ethnopharmacology of medicinal plants used in north Kordofan (western Sudan). Ethnobotanical Leaflets 13 203-210.

EL-Kamali HH \& EL-amir MY 2010 Antibacterial activity and phytochemical screening of ethanolic extracts obtained from selected Sudanese medicinal plants. Current Research Journal of Biological Sciences 2 143-146.

Fenglin H, Ruili L, Bao H \& Liang M 2004 Free radical scavenging activity of extracts prepared from fresh leaves of selected Chinese medicinal plants. Fitoterapia 75 14-23. (doi:10.1016/j.fitote.2003.07.003)

Hakim ZS, Patel BK \& Goyal RK 1997 Effect of chronic ramipril treatment in streptozotocin-induced diabetic rats. Indian Journal of Physiology and Pharmacology 41 353-360.

Hostettmann K \& Marston A 2002 Twenty years of research into medicinal plants: results and perspectives. Phytochemistry Reviews 1 275-285. (doi:10.1023/A:1026046026057)

Kamalakkannan N \& Prince PS 2006 Antihyperglycaemic and antioxidant effect of rutin, a polyphenolic flavonoid, in streptozotocin-induced diabetic Wistar rats. Basic \& Clinical Pharmacology \& Toxicology 98 97-103. (doi:10.1111/j.1742-7843.2006.pto_241.x)

Koko WS, Mesaik MA, Yousaf S, Galal M \& Choudhary MI 2008 In vitro immunomodulating properties of selected Sudanese medicinal plants. Journal of Ethnopharmacology 118 26-34. (doi:10.1016/j.jep.2008.03.007)

Matthews DR, Hosker JP, Rudenski AS, Naylor BA, Treacher DF \& Turner RC 1985 Homeostasis model assessment: insulin resistance and $\beta$-cell function from fasting plasma glucose and insulin concentrations in man. Diabetologia 28 412-419. (doi:10.1007/BF00280883)

Nagarajan NS, Murugesh N, Thirupathy KP, Radha N \& Murali A 2005 Antidiabetic and antihyperlipemic effects of Clemeo feline. Fitoterapia $\mathbf{7 6}$ 310-315. (doi:10.1016/j.fitote.2005.03.020)

Oberley LW 1988 Free radicals and diabetes. Free Radical Biology \& Medicine 5 113-124. (doi:10.1016/0891-5849(88)90036-6)

Pari L \& Saravanan R 2004 Antidiabetic effect of diasulin, an herbal drug, on blood glucose, plasma insulin and hepatic enzymes of glucose metabolism in hyperglycaemic rats. Diabetes, Obesity \& Metabolism 6 286-292. (doi:10.1111/j.1462-8902.2004.0349.x)

Ross SA, el Sayed KA, el Sohly MA, Hamann MT, Abdel-Halim OB, Ahmed AF \& Ahmed MM 1997 Phytochemical analysis of Geigeria alata and Francoeuria crispa essential oils. Planta Medica 63 479-482. (doi:10.1055/s-2006-957743)

Received in final form 16 June 2012

Accepted 25 June 2012

Made available online as an Accepted Preprint 25 June 2012 